\section{Enzymatic activity in turkey, duck, quail and chicken liver microsomes against four human cytochrome P450 prototype substrates and aflatoxin B1}

\author{
Hansen W. Murcia, Gonzalo J. Díaz, \\ Sandra Milena Cepeda \\ Laboratorio de Toxicología, Facultad de \\ Medicina Veterinaria y de Zootecnia, \\ Universidad Nacional de Colombia, \\ Bogotá, D.C., Colombia
}

\section{Abstract}

Cytochrome P450 enzymes (CYP) are a group of monooxygenases able to biotransform several kinds of xenobiotics including aflatoxin B1 (AFB1), a highly toxic mycotoxin. These enzymes have been widely studied in humans and others mammals, but there is not enough information in commercial poultry species about their biochemical characteristics or substrate specificity. The aim of the present study was to identify CYPs from avian liver microsomes with the use of prototype substrates specific for human CYP enzymes and AFB1. Biochemical characterization was carried out in vitro and biotransformation products were detected by high-performance liquid chromatography (HPLC). Enzymatic constants were calculated and comparisons between turkey, duck, quail and chicken activities were done. The results demonstrate the presence of four avian ortholog enzyme activities possibly related with a CYP1A1, CYP1A2, CYP2A6 (activity not previously identified) and CYP3A4 poultry orthologs, respectively. Large differences in enzyme kinetics specific for prototype substrates were found among the poultry species studied. Turkey liver microsomes had the highest affinity and catalytic rate for AFB1 whereas chicken enzymes had the lowest affinity and catalytic rate for the same substrate. Quail and duck microsomes showed intermediate values. These results correlate well with the known in vivo sensitivity for AFB1 except for the duck. A high correlation coefficient between 7-ethoxyresorufin- $O$ deethylase (EROD) and 7-methoxyresorufin$O$-deethylase (MROD) activities was found in the four poultry species, suggesting that these two enzymatic activities might be carried out by the same enzyme. The results of the present study indicate that four prototype enzyme activities are present in poultry liver microsomes, possibly related with the presence of three CYP avian orthologs. More studies are needed in order to further characterize these enzymes.

\section{Introduction}

In order to estimate the activity of individual cytochrome P450 enzymes (CYP) in tissue samples it is necessary to search for specific substrates metabolized by a specific enzyme (or group of enzymes). However, only few prototype substrates have been found and most of them are intended for human CYPs. ${ }^{1}$ Although mammalian and avian CYPs are not strictly orthologs, some substrates, inhibitors and expression inducers have been found to work for both groups ${ }^{2}$ and even for fish. ${ }^{3}$

One of the most important advantages of using selective enzyme substrates is to be able to determine the role of an enzyme in a specific biochemical reaction. ${ }^{4,5}$ The use of this kind of molecules with differential specificities and the effect of these molecules on directed enzymatic reactions has been a useful tool to identify enzymes related with the biotransformation of certain xenobiotics, endogenous metabolites and drugs. ${ }^{6-9}$

A widely used strategy to identify an enzyme involved in a metabolic pathway is to correlate the prototype enzymatic activity with the target substrate molecule activity. ${ }^{10-13}$ In the same way, quantification of enzyme expression by immunoblot and correlation of the amount of protein expressed with the enzyme activity of interest has been used to characterize enzymatic activities. ${ }^{14}$

The current knowledge about the role of poultry CYP enzymes in the metabolism of different xenobiotics and drugs is scarce. ${ }^{15}$ Therefore it is necessary to find new methods and develop new tools in order to characterize enzyme expression and activity in these species. Among commercial poultry species only chicken ${ }^{16}$ and turkey ${ }^{17}$ genomes have been fully sequenced but there is still poor evidence of CYP genes and protein information in other avian species.

Of particular importance are the enzymes responsible for the bioactivation of compounds such as aflatoxin B1 (AFB1), a toxic compound produced by certain strains of Aspergillus flavus and A. parasiticus. This mycotoxin is bioactivated by CYP enzymes to a more toxic form called AFB1-8,9-exo-epoxide (AFB0) that causes deleterious effects on both poultry and human health. ${ }^{18,19}$ CYP1A, CYP2A6 and CYP3A enzymes have been reported as responsible for the bioactivation of $\mathrm{AFB}^{20-23}$ in humans. The aim of the present study was to identify human ortholog activities in liver microsomes of four poultry species by the use of human CYP prototype substrates and AFBland to compare the $\mathrm{K}_{\mathrm{M}}$ and $V_{\max }$ constants obtained.
Correspondence: Hansen W. Murcia, Laboratorio de Toxicología, Facultad de Medicina Veterinaria y de Zootecnica, Universidad Nacional de Colombia, Ciudad Universitaria, Bogotá, D.C., Colombia.

Tel: +57.1 .316 .5000 ext. 19450

Fax: +57.1.316.5000 ext. 19467

E-mail: hwmurciag@unal.edu.co

Key words: CYP prototype substrates, avian CYP, aflatoxin B1, enzymatic parameters, avian CYP2A6 ortholog.

Acknowledgments: the authors would like to thank the International Foundation for Science (Stockholm, Sweden) for partial funding of our research on in vitro metabolism of aflatoxin B1, to all people involved in this work and to the National University of Colombia in Bogotá, our second home.

Contributions: HWM, experimental procedures developing, data collecting and analyzing, manuscript drafting; GJD, article revising; SMC, experimental procedures supporting, data analyzing.

Conflict of interest: the authors report no conflicts of interest.

Received for publication: 27 July 2011. Accepted for publication: 27 September 2011.

This work is licensed under a Creative Commons Attribution NonCommercial 3.0 License (CC BYNC 3.0).

(C) Copyright H.W. Murcia et al., 2011

Licensee PAGEPress, Italy

Journal of Xenobiotics 2011; 1:e4

doi:10.4081/xeno.2011.e4

\section{Materials and Methods}

\section{Reagents}

AFB1, AFB $2_{\alpha}$, TRIS, Tween 20, glucose 6phosphate sodium salt, glucose 6-phosphate dehydrogenase, ethylenediaminetetraacetic acid (EDTA), bicinchoninic acid, copper sulfate, sucrose, glycine, NADP sodium salt hydrate, glycerol, bovine serum albumin, methoxyresorufin, $\alpha$-naphthoflavone, $\quad 8$ methoxypsoralen and 7-hydroxycoumarin were purchased from Sigma Chemical Co (St. Louis, M0, USA). Sodium chloride and magnesium chloride hexahydrate were from Mallinckrodt Baker (Phillipsburg, NJ, USA). Sodium dihydrogen phosphate monohydrate and di-sodium hydrogen phosphate anhydrous were from Merck (Darmstadt, Germany). Nifedipine and oxidized nifedipine were purchased from BDBiosciences (San Jose, CA, USA). Coumarin, ethoxyresorufin and resorufin sodium salt were purchased from MP Biomedicals (Solon, 
OH, USA). Methanol, acetonitrile, water and other solvents used in preparing mobile phases were all HPLC grade.

\section{Liver samples}

All experiments were carried out at $4^{\circ} \mathrm{C}$. Six healthy 6-week old quail (three males and three females), six healthy 6 -week old chickens (three males and three females), six healthy 6-week old Pekin ducks (three males and three females) and six healthy 6-week turkeys (three males and three females) obtained from local commercial growers were euthanized and their livers extracted immediately, according to international policies and ethics. The livers were washed with cold PBS buffer (20 mM phosphates $\mathrm{pH} 7.4,100 \mathrm{mM}$ $\mathrm{NaCl}$ ) and stored at $-70^{\circ} \mathrm{C}$ until processing.

\section{Microsome extraction}

For microsome extraction $5 \mathrm{~g}$ of frozen liver samples were carefully minced and homogenized with $10 \mathrm{~mL}$ of cold PBS buffer (20 mM phosphates pH 7.4 with $1 \mathrm{mM}$ EDTA and 250 $\mathrm{mM}$ sucrose) for $30 \mathrm{~s}$ using a tissue homogenizer (IKA Ultra-Turrax, Staufen, Germany). The homogenate was then centrifuged at $10000 \mathrm{x}$ g for $30 \mathrm{~min}$ at $4^{\circ} \mathrm{C}$. The supernatant (10 $\mathrm{mL}$ approximately) was collected and transferred to ultracentrifuge tubes kept at $4^{\circ} \mathrm{C}$ and centrifuged for $90 \mathrm{~min}$ at $98,000 \mathrm{x}$ g at $4^{\circ} \mathrm{C}$. Supernatants (cytosolic fraction) were collected for further studies and the resulting pellet was resuspended in $3 \mathrm{~mL}$ of storage buffer (20 $\mathrm{mM}$ phosphate buffer $\mathrm{pH}$ 7.4, 1 mM EDTA, 250 $\mathrm{mM}$ sucrose and $20 \%$ glycerol) and aliquoted in microcentrifuge tubes. Aliquotes were stored at $-70^{\circ} \mathrm{C}$ until in vitro assays were carried out. An aliquot was used to determine the protein content by the bicinchoninic acid protein quantification method. ${ }^{24}$

\section{Microsomal incubations}

Microsomal incubations were carried out in $1.5 \mathrm{~mL}$ microcentrifuge tubes at $39^{\circ} \mathrm{C}$. Incubations contained $5 \mathrm{mM}$ glucose 6-phosphate, $0.5 \mathrm{mM} \mathrm{NADP}+$, 0.5 I.U. glucose 6-phosphate dehydrogenase, $2 \mu \mathrm{L}$ of AFB1 or the different substrates dissolved in DMSO,20, 50, 75 or $100 \mu \mathrm{g}$ of quail, turkey, duck and chicken microsomal protein, respectively and incubation buffer (50 mM phosphate buffer, $\mathrm{pH} 7.4,5$ $\mathrm{mM} \mathrm{MgCl}$ and $0.5 \mathrm{mM}$ EDTA) to a final volume of $250 \mu \mathrm{L}$. Organic solvent concentration did not exceed $1 \% .{ }^{25}$ Blanks were used to verify the possible inhibiting effects of DMSO. Reactions were stopped after $10 \mathrm{~min}$ of incubation with $250 \mu \mathrm{L}$ ice cold acetonitrile ${ }^{26}$ and centrifuged at $12,000 \mathrm{x} g$ for $10 \mathrm{~min}$. Depending on the specific detector response of the substrate and/or product from the incubation; dilutions of the supernatant were made before injection into the HPLC as described below.

\section{Enzymatic activity of selected CYP prototype substrates}

The following prototype enzymatic activities were determined using HPLC: 7-ethoxyresorufin- $O$-deethylase (EROD) for CYP1A1 and $1 \mathrm{~A} 2$ (CYP1A1/2), 7-methoxyresorufin-0demethylase (MROD) for CYP1A2, coumarin 7hydroxylase for CYP2A6, and nifedipine oxidation for CYP3A4. The amount of product formed by each enzymatic activity was quantified using a Shimadzu HPLC Prominence System (Shimadzu Scientific Instruments, Columbia, MD, USA) equipped with a DGU20A3 Degasser, an LC-20AB pump, a SIL-20A HT autosampler, a CTO-20A column oven, an SPD-20AV UV-Vis detector, an RF-10A XL fluorescence detector, and a CBM-20A bus module, all controlled by $L C$ Solutions software. All separations were carried out with an Alltech Alltima HP C18 $5 \mu \mathrm{m}$ column, $150 \mathrm{~mm} \times 3.0$ mm (Alltech Associates Inc., Deerfield, IL, USA).

\section{Chromatographic conditions}

Determination of 7-ethoxyresorufin and its product resorufin (EROD activity) was carried out at room temperature, at a flow rate of 0.3 $\mathrm{mL} / \mathrm{min}$ using an isocratic mobile phase consisting of $30 \%$ phosphate buffer $(20 \mathrm{mM}$ phosphate, $\mathrm{pH} 7.4$ ) and $70 \%$ methanol. The analytes were monitored using fluorescence detection at excitation and emission wavelengths of 530 and $580 \mathrm{~nm}$, respectively. The incubation supernatant was diluted 1:10 with water and 5 $\mu \mathrm{L}$ of the dilute sample were injected into the chromatograph.

The same conditions were used for the determination of 7-methoxyresorufin and its product resorufin (MROD activity), except that only $2 \mu \mathrm{L}$ of the dilute sample were injected into the chromatograph.

Determination of coumarin and its hydroxylated metabolite 7-hydroxycumarin (CYP2A6 activity) was carried out at room temperature, at a flow rate of $0.4 \mathrm{~mL} / \mathrm{min}$ using an isocratic mobile phase consisting of $30 \%$ acetonitrile and $70 \%$ water. The two compounds were monitored using fluorescence detection at excitation and emission wavelengths of $325 \mathrm{~nm}$ and $452 \mathrm{~nm}$, respectively. Supernatants were diluted 1:100 with water and $5 \mu \mathrm{L}$ of the dilute sample were injected into the chromatograph.

Determination of nifedipine and its metabolite oxidized nifedipine (CYP3A4 activity) was carried out at room temperature, at a flow rate of $0.5 \mathrm{~mL} / \mathrm{min}$ using an isocratic mobile phase consisting of $32 \%$ acetonitrile and $68 \%$ water. The analytes were monitored by UV detection at $270 \mathrm{~nm}$ and $10 \mu \mathrm{L}$ of the supernatant were injected directly into the chromatograph without further dilution.

AFB1-dhd and AFB1 identification was carried out at $40^{\circ} \mathrm{C}$, at a flow rate of $0.35 \mathrm{~mL} / \mathrm{min}$.
The AFBO production was monitored as the AFB1-dhd adduct, which was quantified using AFB2 $\alpha$ as standard (given the similar spectral properties of AFB1-dhd and AFB2 $\alpha$ ). The compounds were separated using a linear gradient of A: water- $0.1 \%$ formic acid and B: methanol$0.1 \%$ formic acid, as follows: 0 min: $30 \% \mathrm{~B}, 2$ min: 30\% B, 7 min: $55 \%$ B; 7.01 min: 30\% B. The two analytes were monitored by fluorescence detection at excitation and emission wavelengths of 365 and $425 \mathrm{~nm}$, respectively. A 1:100 dilution was made from which $2 \mu \mathrm{L}$ were injected into the chromatograph.

\section{Determination of enzymatic kinetic parameters}

In order to estimate the relative $\mathrm{K}_{\mathrm{M}}$ and $V_{\max }$ values of the selected CYP orthologs, each prototype substrate and AFB1 were incubated in three randomLy selected microsome samples from both male and female birds in duplicate. For EROD activity (CYP1A1/2) concentrations ranging from 4.8 to $0.3 \mu \mathrm{M}$ of 7 -ethoxyresorufin were used, for MROD activity (CYP1A2) concentrations from 5.88 to $0.36 \mu \mathrm{M}$ of 7-metoxyresorufin were used, for coumarin 7-hydroxylase activity (CYP2A6) concentrations from 80 to $5 \mu \mathrm{M}$ of coumarin were used, and for nifedipine oxidation (CYP3A4) concentrations from 71.0 to $4.4 \mu \mathrm{M}$ of nifedipine were used. To investigate AFB1 epoxidation activity, concentrations from 256 to $16 \mu \mathrm{M}$ of AFB1 were used.

\section{Statistical analysis}

The enzymatic parameters $\mathrm{K}_{\mathrm{M}}$ and $V_{\max }$ were determined by nonlinear regression using the Marquardt method adjusting the data to Michaelis-Menten enzyme kinetics using the equation: $\mathrm{v}=V_{\max }[\mathrm{S}] /\left(\mathrm{K}_{\mathrm{M}}+[\mathrm{S}]\right)$, where $\mathrm{v}$ is the enzyme reaction velocity, [S] represents substrate concentration, $V_{\max }$ represents maximal velocity and $\mathrm{K}_{\mathrm{M}}$ represents the MichaelisMenten constant. ${ }^{27,28}$ Nonlinear regression fitting was accomplished with the use of the following weighting function: $\omega=1 / \mathrm{yi}^{\alpha}$, where yi is the velocity for each substrate concentration and $\alpha$ the magnitude of relation between residuals and variance. ${ }^{28,29}$

The CYP mediated production of the different biotransformation products is expressed as the mean \pm standard deviation of six birds (three males and three females). Comparisons were carried out between sexes and between species by a t-test with a significance level of 0.05 . Pearson correlation coefficients were computed for EROD vs MROD activity in all species studied. Calculations were performed using the Statistical Analysis System software..$^{30}$ 


\section{Results}

To compare activities between species, data from males and females were pooled since no significant differences between sexes were found. However, significant interspecies differences in enzyme kinetics by substrate were observed for several orthogonal comparisons (Table 1).

Figure 1 shows the enzymatic constants $\mathrm{K}_{\mathrm{M}}$ and $V_{\max }$ and the enzyme kinetics for the four avian species studied. For AFB1 epoxidation, apparent $\mathrm{K}_{\mathrm{M}}$ and $V_{\max }$ values ranged from 23.35 to $170.85 \mu \mathrm{M}$ and from 2.05 to $5.90 \mathrm{nmol} / \mathrm{mg}$ protein/min, respectively. $\mathrm{K}_{\mathrm{M}}$ and $V_{\max }$ values for EROD activity ranged from 0.39 to $2.55 \mu \mathrm{M}$ and from 0.03 to $0.72 \mathrm{nmol} / \mathrm{mg}$ protein $/ \mathrm{min}$, respectively. MROD enzymatic activity resulted in $\mathrm{K}_{\mathrm{M}}$ values ranging from 0.46 to $7.37 \mu \mathrm{M}$ and $V_{\max }$ values from 0.06 to $2.27 \mathrm{nmol} / \mathrm{mg}$ protein/min. The $K_{M}$ value for coumarin hydroxylation ranged from 4.9 to $64.7 \mu \mathrm{M}$, whereas the $V_{\max }$ values ranged from 0.3 to $1.3 \mathrm{nmol} / \mathrm{mg}$ protein/min. Nifedipine oxidation enzyme constants ranged from 3.46 to $32.60 \mu \mathrm{M}$ for $\mathrm{K}_{\mathrm{M}}$ and from 1.3 to $7.2 \mathrm{nmol} / \mathrm{mg}$ protein $/ \min$ for $V_{\max }$.

The highest AFBO production rate was observed for turkey microsomes, while chicken showed the lowest rate. Duck and quail presented intermediate values. EROD activity was also highest in turkey microsomes, while chicken showed the lowest EROD activity. Duck and quail again presented intermediate values. This same trend was also observed for MROD activity. In the case of 7-coumarin hydroxylation, the quail and duck CYP2A6 orthologs had the highest affinity for this substrate but coumarin 7-hydroxylation activity was significantly higher in quail than in duck microsomes. The chicken and turkey orthologs presented medium and low affinity for the same enzymatic activity, respectively. Quail nifedipine oxidation activity was the highest followed by turkey and duck; chicken presented the lowest activity.

EROD and MROD activities showed a similar trend in all species studied with higher enzyme constant values for the 7-methoxyresorufin- $O$-deethylation activity than for 7 ethoxyresorufin- $O$-deethylation activity. This finding prompted us to investigate the rela-

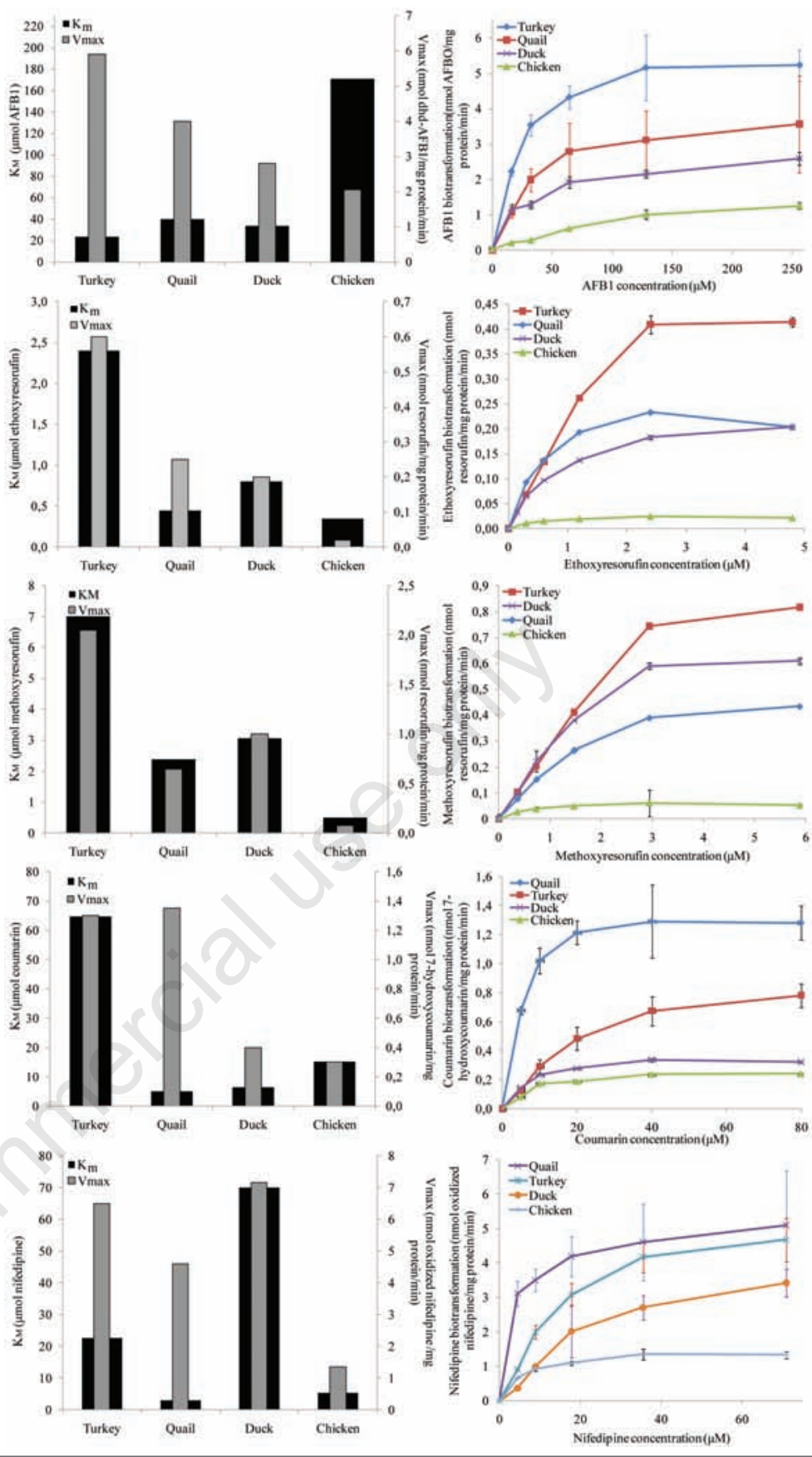

Figure 1. Enzymatic constants $K_{m}$ and Vmax obtained by nonlinear regression (left) and Michaelis-Menten kinetics obtained from experimental data (right) for CYP avian orthologs. Enzyme activities from top to bottom are AFB1 epoxidase, 7-ethoxyresorufinO-deethylase (EROD), 7-methoxyresorufin-O-deethylase (MROD), coumarin 7-hydroxylase and nifedipine oxidase. Enzymatic constants KM and Vmax are graphed in black and gray, respectively. In Michaelis-Menten kinetics each point represents the mean \pm standard deviation of 6 birds.

Table 1. Orthogonal contrasts of enzyme kinetics among four commercial poultry species. Only values that are statistically different $(P<0.05)$ are shown.

\begin{tabular}{|c|c|c|c|c|c|c|c|c|}
\hline Substrate & Avian Species & $\mathbf{P}$ & Substrate & Avian Species & $\mathbf{P}$ & Substrate & Avian Species & P value \\
\hline \multirow[t]{4}{*}{ Aflatoxin B1 } & Turkey - Chicken & 0.007 & \multirow[t]{4}{*}{ Ethoxyresorufin } & Turkey - Chicken & 0.019 & \multirow[t]{4}{*}{ Methoxyresorufin } & Turkey - Chicken & 0.028 \\
\hline & Turkey - Duck & 0.037 & & Turkey - Duck & 0.094 & & Quail - Chicken & 0.025 \\
\hline & Quail - Chicken & 0.020 & & Quail - Chicken & 0.007 & & Chicken - Duck & 0.021 \\
\hline & Chicken -Duck & 0.025 & & Chicken - Duck & 0.011 & & & \\
\hline \multirow[t]{3}{*}{ Coumarin } & Turkey - Quail & 0.031 & \multirow[t]{3}{*}{ Nifedipine } & Turkey - Chicken & 0.044 & & & \\
\hline & Quail - Chicken & 0.008 & & Quail - Chicken & 0.008 & & & \\
\hline & Quail - Duck & 0.008 & & Quail - Duck & 0.039 & & & \\
\hline
\end{tabular}


tionship between these two enzymatic activities by correlating 7-ethoxyresorufin- $\boldsymbol{O}$ deethylase activity against 7-methoxyresorufin- $\boldsymbol{O}$-deethylase activity (Figure 2). Pearson correlation coefficients and $P$ values for turkey, quail, duck and chicken microsomes were $0.88(\mathrm{P}=0.0001), 0.60(\mathrm{P}=0.0400), 0.95$ $(\mathrm{P}=0.0000)$ and $0.84(0.0006)$, respectively.

\section{Discussion}

The results of the present study support the notion that phase I biotransformation by CYP enzymes plays a significant role in the large in vivo differences in susceptibility against the AFB1 observed among poultry species but that other variables must also play a role. For example, ducks are known for their extreme sensitivity to AFB1 in vivo and our results demonstrate that duck microsomes have a very high enzyme affinity for AFB1; however, the catalytic rate for AFB0 production was lower compared to turkey or quail microsomes. These findings suggest that the extreme sensitivity of ducks to AFB1 cannot be explained solely on the basis of the bioactivation of AFB1 into AFBO (phase I metabolism). Future studies of enzymes involved in phase II metabolism are needed to elucidate and give a more precise explanation about the sensitivity shown by each poultry species against AFB1.

In regards to prototype substrate activities, studies with human liver microsomes have shown EROD activity $\mathrm{K}_{\mathrm{M}}$ and $V_{\max }$ values of $0.162 \mu \mathrm{M}$ and $0.028 \mathrm{nmol} / \mathrm{mg}$ protein $/ \mathrm{min}$, respectively; for MROD activity a $\mathrm{K}_{\mathrm{M}}$ value of
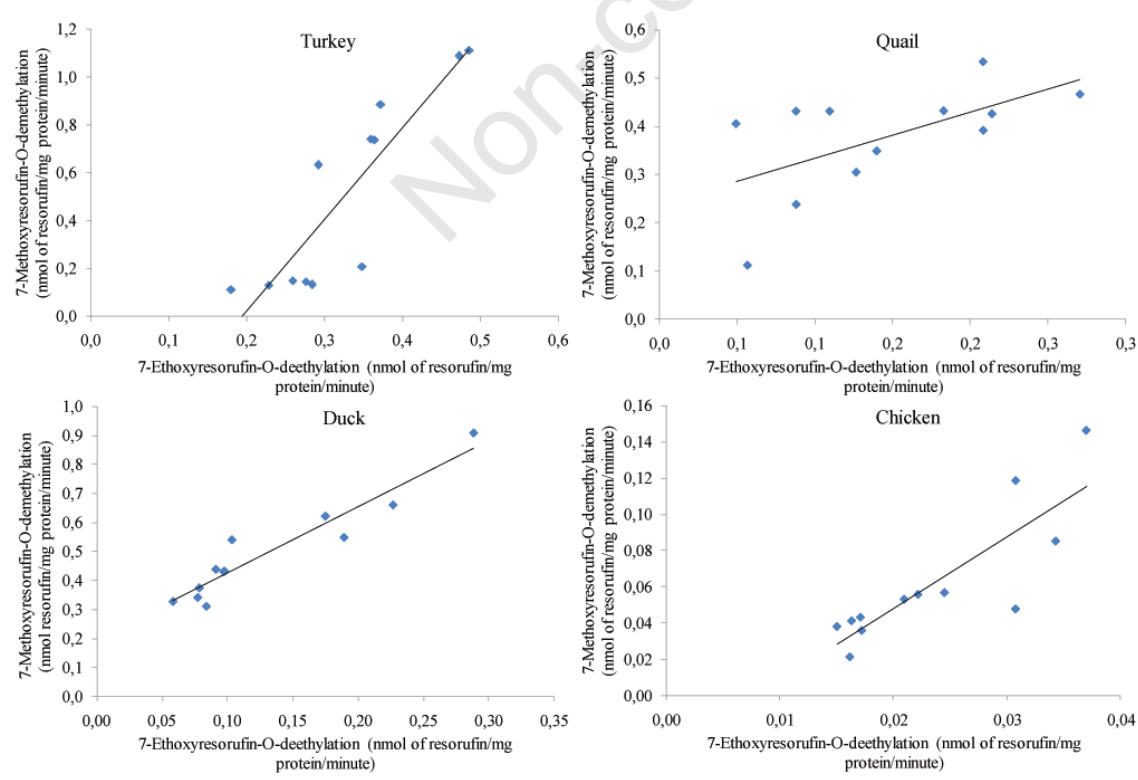

Figure 2. Linear regression of 7-Ethoxyresorufin- $O$-deethylase (EROD) vs 7-methoxyresorufin-O-deethylase (MROD) activities in liver microsomes $(n=12)$ in four commercial poultry species. Correlation coefficients and level of significance are shown in the text. similarity with the human counterparts, the turkey CYP1A5 has 61\% homology compared with the human CYP1A1 and 62\% homology compared with the human CYP1A2. Human CYP1A1 has a $62.4 \%$ homology compared with chicken CYP1A1 and 60\% with chicken CYP1A4; human CYP1A2 and chicken 1A4 have $56 \%$ homology. In regards to members of the 3 A subfamily, the human CYP3A5 has a $59 \%$ homology compared with turkey CYP3A37, human CYP3A4 a 59\% homology compared with turkey CYP3A37, human CYP3A7 a 58\% homology compared with turkey CYP3A37, human CYP3A43 a 56\% homology compared with turkey CYP3A37 and human CYP3A4 a $61.1 \%$ homology compared with chicken CYP3A80. The presence of enzymatic activity and homologous sequences in both humans and poultry strongly suggests the existence of the CYP orthologs studied in the present study in poultry liver microsomes. To have a better understanding of the role of these enzymes on the bioactivation of compounds such as AFBlit is necessary to further characterize the genes that encode these proteins in all poultry species, specially the gene that encodes the CYP2A6 ortholog since there is no information about this gene in poultry. An interesting finding of the present study is the high correlation between EROD and MROD activities in all poultry liver microsomes studied. This close relationship suggests either the existence of an overlapping activity of two separate enzymes or that MROD and EROD activities are catalyzed by a unique CYP1A avian ortholog with different affinities and catalytic rates against each prototype substrate. This issue needs to be further investigated.

The results of the present study show CYP activity against prototype substrates used in human experiments suggesting the existence of avian CYP orthologs of the human enzymes studied. These results also confirm that the differences in sensitivity to AFB1 among poultry species can be partially explained by differences in the relative enzymatic properties of the CYP avian orthologs responsible for AFB1 bioactivation. ${ }^{35}$ This study also shows that the turkey liver microsomes are the most efficient bioactivating AFB1 to AFB0, followed by quail, duck and chicken enzymes. In order to completely understand how AFB1 is biotransformed in avian species and how metabolism determines in vivo sensitivity it is necessary to further investigate phase I and specially phase II metabolism of AFB1 in poultry.

\section{References}

1. Josephy PD. Molecular toxicology. New York: Oxford University Press; 1997.

2. Chauret N, Gauthier A, Martin J, Nicoll- 
Griffith DA. In vitro comparison of cytochrome P450-mediated metabolic activities in human, dog, cat, and horse. Drug Metab Dispos 1997;25:1130-6.

3. Renauld AE, Melancon MJ, Sordillo LM. Identification of in vitro cytochrome P450 modulators to detect induction by prototype inducers in the mallard duckling (Anas platyrhynchos). Comp Biochem Physiol C Pharmacol Toxicol Endocrinol 1999;122:273-81.

4. Halpert JR, Guengerich FP, Bend JR, Correia MA. Selective inhibitors of cytochromes P450. Toxicol Appl Pharmacol 1994;125:163-75.

5. Pelkonen 0, Turpeinen M, Hakkola J, et al. Inhibition and induction of human cytochrome P450 enzymes: current status. Arch Toxicol 2008;82:667-715.

6. Henderson MC, Miranda CL, Stevens JUF, Deinzer ML, Buhler DR. In vitro inhibition of human P450 enzymes by prenylated flavonoids from hops, Humulus lupulus. Xenobiotica 2000;30:235-51.

7. Donato MT, Jiménez N, Castell JV, GómezLechón MJ. Fluorescence-based assays for screening nine cytochrome P450 (P450) activities in intact cells expressing individual human P450 enzymes. Drug Metab Dispos 2004;32:699-706.

8. Peng JZ, Remmel RP, Sawchuk RJ. Inhibition of murine cytochrome P4501A by tacrine: in vitro studies. Drug Metab Dispos 2004;32:805-12.

9. Appiah-Opong R, Commandeur JN, van Vugt-Lussenburg B, Vermeulen NP. Inhibition of human recombinant cytochrome P450s by curcumin and curcumin decomposition products. Toxicology 2007;235:83-91.

10. McManus ME, Boobis AR, Minchin RF, et al. Relationship between oxidative metabolism of 2-acetylaminofluorene, debrisoquine, bufuralol, and aldrin in human liver microsomes. Cancer Res 1984;44:5692-7.

11. Kenworthy KE, Bloomer JC, Clarke SE, Houston JB. CYP3A4 drug interactions: correlations of 10 in vitro probe substrates. Br J Clin Pharmacol 1999;48:716-27.

12. Sy SK, Tang B, Pastrakuljic A, et al. Detail characterization of experimental derived human hepatic CYP1A1 activity and expression using differential inhibition of ethoxyresorufin 0-deethylation by fluvoxamine. Eur J Pharmacol 2001;57:377-86.

13. Quintieri L, Geroni C, Fantin M, et al. Formation and antitumor activity of PNU159682, a major metabolite of nemorubicin in human liver microsomes. Clin Cancer Res 2005;11:1608-17.

14. Díaz GJ, Squires EJ. Metabolism of 3methylindole by porcine liver microsomes: responsible cytochrome P450 enzymes. Toxicol Sci 2000;55:284-92.

15. Šavlík M, L. Poláčkcová, Szotáková B, et al. Activities of biotransformation enzymes in pheasant (Phasianus colchicus) and their modulation by in vivo administration of mebendazole and ubendazole. Res Vet Sci 2007;83:20-6.

16. International Chicken Genome Sequencing Consortium. Sequence and comparative analysis of the chicken genome provide unique perspectives on vertebrate evolution. Nature 2004;432:695716.

17. Dalloul RA, Long JA, Zimin AV, et al. Multiplatform next-generation sequencing of the domestic turkey (Meleagris gallopavo): genome assembly and analysis. PLoS Biol 2010;8. pii: e1000475.

18. Leeson S, Díaz GJ, Summers JD. Poultry metabolic disorders and mycotoxins. Guelph. Ontario: University Books; 1995.

19. Hussein HS, Brasel JM. Toxicity, metabolism, and impact of mycotoxins on humans and animals. Toxicol 2001;167:101-34.

20. Eaton DL, Gallagher EP. Mechanisms of aflatoxin carcinogenesis. Annu Rev Pharmacol Toxicol 1994;34:135-72.

21. Verma RJ. Aflatoxin causes DNA damage. Int J Hum Genet 2004;4:231-6.

22. Do JH, Choi D. Aflatoxins: detection, toxicity, and biosynthesis. Biotechnol Bioprocess Eng 2007;12:585-93.

23. Ferguson LR, Philpott M. Nutrition and mutagenesis. Annu Rev Nutr 2008;28:31329.

24. Redinbaugh MG, Turley RB. Adaptation of the bicinchoninic acid protein assay for the use with microtiter plates and sucrose gradient fractions. Anal Biochem 1986; 153:267-71.

25. Busby WF, Ackermann JM, Crespi CL. Effect of methanol, ethanol, dimethyl sulphoxide and acetronitrile on in vitro activities of cDNA-expressed human cytochromes P-450. Drug Metab Dispos 1999;27:246-9.

26. Blanchard J. Evaluation of the relate efficacy of various techniques for deproteinizing plasma samples prior to high-performance liquid chromatography analysis. J Chromatogr 1981;226:455-60.

27. Bisswanger H. Enzyme kinetics. Principles and methods. 2nd, Revised and Updated Edition. Weinheim, Germany: Wiley-VCH Verlag GmbH \& Co. KGaA; 2003.

28. Marangoni AG. Enzyme kinetics. A modern approach. Hoboken. New Jersey: Wiley Interscience. John Wiley \& Sons, Inc; 2008.

29. Kakkar T, Boxenbaum H, Mayersohn M. Estimation of Ki in a competitive enzymeinhibition model: comparisons among three methods of data analysis. Drug Metab Dispos 1999;27:756-62.

30. SAS Institute Inc. SAS/STAT® 9.2 User's Guide. Cary, NC: SAS Institute Inc. 2008.

31. Hanioka N, Tatarazako N, Jinno H, et al. Determination of cytochrome P450 1A activities in mammalian liver microsomes by high-performance liquid chromatography with fluorescence detection. J Chromatogr B Biomed Sci Appl 2000;744:399-406.

32. Yamasaki H, Tanaka M, Shimada T. Highly sensitive high-performance liquid chromatographic assay for coumarin 7-hydroxylation and 7-ethoxycoumarin 0-deethylation by human liver cytochrome P450 enzymes. J Chromatogr B Biomed Sci Appl 1999;721:13-9.

33. Patki KC, von Moltke LL, Greenblatt DJ. In vitro metabolism of midazolam, triazolam, nifedipine, and testosterone by human liver microsomes and recombinant cytochromes P450: role of CYP3A4 and CYP3A5. Drug Metab Dispos 2003;31:93844.

34. Klaassen CD (Ed). Casarett and Doull's Toxicology - The Basic Science of Poisons. 7th Ed. New York: McGraw Hill Medical; 2008. pp. 180-190.

35. Lozano MC, Díaz GJ. Microsomal and cytosolic bioactivation of aflatoxin B1 in four poultry species. Br Poult Sci 2006;47: 734-41. 